\title{
Impacts of highly automated vehicles on travel demand: macroscopic modeling methods and some results
}

\author{
Jörg Sonnleitner $^{1}$ (D) Markus Friedrich $^{1}$ (D) Emely Richter ${ }^{1}$ (D)
}

Accepted: 4 June 2021 / Published online: 11 June 2021

(c) The Author(s) 2021

\begin{abstract}
Automated vehicles (AV) will change transport supply and influence travel demand. To evaluate those changes, existing travel demand models need to be extended. This paper presents ways of integrating characteristics of AV into traditional macroscopic travel demand models based on the four-step algorithm. It discusses two model extensions. The first extension allows incorporating impacts of AV on traffic flow performance by assigning specific passenger car unit factors that depend on roadway type and the capabilities of the vehicles. The second extension enables travel demand models to calculate demand changes caused by a different perception of travel time as the active driving time is reduced. The presented methods are applied to a use case of a regional macroscopic travel demand model. The basic assumption is that AV are considered highly but not fully automated and still require a driver for parts of the trip. Model results indicate that first-generation AV, probably being rather cautious, may decrease traffic performance. Further developed AV will improve performance on some parts of the network. Together with a reduction in active driving time, cars will become even more attractive, resulting in a modal shift towards car. Both circumstances lead to an increase in time spent and distance traveled.
\end{abstract}

Keywords Automated vehicles - Macroscopic travel demand model · Traffic performance · Perception of time $\cdot$ CoEXist

\section{Introduction}

Automated vehicles (AV) will change transport supply and influence travel demand. Obviously, fully automated vehicles will have the biggest impact in this respect, since they can operate driverless under all conditions. However, until driverless vehicles will be ready to

Jörg Sonnleitner

joerg.sonnleitner@isv.uni-stuttgart.de

Markus Friedrich

markus.friedrich@isv.uni-stuttgart.de

Emely Richter

emely.richter@isv.uni-stuttgart.de

1 Institute for Road and Transport Science, Chair for Transport Planning and Traffic Engineering, Pfaffenwaldring 7, 70569 Stuttgart, Germany 
serve the entire road network according to Level 5 of the SAE standard (SAE International 2018), some generations of partly and highly automated vehicles will precede them and will have to coexist with conventional vehicles $(\mathrm{CV})$ for a presumably long time. This situation may arise soon, as these AV, being not yet fully automated, could be considered as a further development of today's vehicles with driver assistance functions that are already available.

Due to potential differences regarding driving behavior compared to $\mathrm{CV}$, highly automated vehicles will influence traffic flow and network performance. Furthermore, the comfort for the driver to hand over the driving task to the car on certain parts of the road network and to use this time for other activities will have additional effects on travel demand.

Many cities and regions operate macroscopic travel demand models based on the fourstep approach (Bates 2008) to quantify the impacts of supply changes on travel demand. The demand effects of AV depend on many variables for which the properties are insufficiently or not known at all today. Some important variables result from the effects of AV on the throughput of roads and on the perception of travel time. Travel demand models provide a framework for systematically investigating changes of these influencing variables' values and thus allow to estimate possible associated effects. Integrating AV into macroscopic travel models requires adjustments to existing modeling methods.

This paper presents model extensions that enable model users to examine the impacts of highly automated vehicles in existing macroscopic travel demand models for passenger transport. The extensions cover the following areas of application:

- Modeling the impact of automated vehicles on traffic flow performance.

- Estimating the demand effects of highly automated vehicles that can drive automated on parts of the network, but still require a driver with a driving license.

- Quantifying the impact of highly automated vehicles on distance traveled (person and vehicle kilometers) and time spent (person and vehicle hours) in a study area.

- Analyzing the effects of regulatory measures, e.g. policy-related restrictions for AV to operate automated on certain road sections.

To show the usability of the proposed model extensions, they are applied to the macroscopic travel demand model of the Stuttgart Region in Germany. Model extensions and applications are a result of the research project CoEXist (h2020-coexist.eu), which aims at providing macroscopic and microscopic modeling tools and travel demand models that incorporate the properties of AV. The project was funded by the EU within the Horizon 2020 research and innovation program.

\section{Literature review}

Transport models can help planners and decision-makers to better understand the potential impacts of AV. Modeling research in the context of AV so far mainly focuses either on microscopic traffic flow models or on microscopic travel demand models, i.e. models following an agent-based approach.

The latter are used in numerous studies to analyze the impact of automated ridesharing systems on a given travel demand scenario, e.g. Bischoff et al. (2017), Heilig et al. (2017), Fagnant and Kockelman (2018) and Hörl et al. (2019b). In these studies, driverless and shared automated vehicles (SAV) typically replace a given part or even the whole fleet 
of privately-owned cars. The models are then applied to estimate the required size of the SAV fleet, the effects on overall vehicle mileage and the quality of the service. Since this paper focuses on highly automated vehicles in private ownership, such SAV-related studies are not discussed further. Soteropoulos et al. (2019) provide a good overview on modeling studies dealing with impacts of $\mathrm{AV}$, including in particular studies on SAV fleets.

\section{Capacity impacts}

There is a very broad spectrum of studies applying microscopic traffic flow models to estimate impacts of AV on capacity with different focuses, assumptions and results. Shladover et al. (2012) and Talebpour and Mahmassani (2016) distinguish in their studies between vehicles with autonomous and connected driving functionality. One of their results is that connectivity can increase capacity by up to $100 \%$ on freeways. Hartmann et al. (2017) examine the impact of different vehicle automation levels on traffic flow and find positive effects only for connected AV keeping small headways. Accordingly, the capacity gains on freeway segments vary between $0 \%$ for weaving sections and $40 \%$ for freeway sections excluding on- and off-ramps. A study by Fernandes and Nunes (2010) suggests that capacity could potentially multiply in comparison to today. However, they assume AV to drive exclusively in platoons with a spacing of one meter and no CV at all. Tientrakool et al. (2011) distinguish between AV with and without vehicle-to-vehicle (V2V) communication. They find capacity gains for highways of $43 \%$ without and of $273 \%$ with V2V-communication. The increase is a function of the share of the respective type of AV with its maximum for $100 \% \mathrm{AV}$. Lu et al. (2019) simulate fully automated vehicles maintaining a gap of $0.6 \mathrm{~s}$ in an artificial and a real network with intersections and determine a $16 \%$ to $24 \%$ increase in capacity overall. Le Vine et al. (2015) take a different approach, assuming that AV only drive within the limits of the maximum acceleration and deceleration values maintained by rail systems. They argue that this driving behavior provides a reasonable ride comfort, but will decrease intersection capacity and increase delay.

Many studies suggest benefits related to capacity only at high AV penetration rates. In contrast, Stern et al. (2018) show that also few, "intelligent" AV can harmonize and stabilize traffic flow in specific traffic situations like stop-and-go-waves.

Common to all mentioned studies is the assumption that AV with their specific vehicle following and lane changing behavior will influence traffic flow and affect the traffic performance of road facilities. These effects, which depend on the characteristics and the share of the $\mathrm{AV}$, must be replicated in assignment and traffic flow models. Examples for such extensions can be found for assignment models in Friedrich et al. (2019), for macroscopic traffic flow models in Friedrich (2016) and microscopic traffic flow models in Wagner (2016) and Sukennik et al. (2018a).

\section{Perception of travel time with AV}

Travel demand models replicate the decision-making processes that lead to trips in the transport network. The traditional four-step model covers the steps of trip generation, destination choice, mode choice and route choice in passenger transport (Bates 2008). For each choice situation, travelers select from a set of alternatives. A utility function represents the utility of each alternative considering the characteristics of the trip maker (user group) and the trip purpose (activity). Utility functions include various time components (access, egress, in-vehicle, waiting, parking search), cost and travel comfort. Each of these 
components is weighted by a specific parameter. For already existing transport modes, these parameters can be estimated using observed choices recorded in mobility surveys. Setting the car-driver's parameter value of in-vehicle time (VOT) for trips with AV requires assumptions (e.g. that the value is similar to the value of a train user or a car passenger) or observations collected in stated preference surveys.

Studies using stated preference surveys (Looff et al. 2018; Correia et al. 2019) or surveys combining revealed and stated preference (Steck et al. 2018) find reductions for the VOT for commuting and long-distance trips in AV ranging from 10 to 30\% compared to CV. For (short) leisure and shopping trips, Correia et al. (2019) and Steck et al. (2018) find small or no changes, while Looff et al. (2018) suggests a higher VOT. According to Flügel et al. (2019), the reduction for the VOT in AV is $21 \%$ on average, with a greater impact for full automation compared to partial automation and more perceived benefits in privatelyowned AV as in shared ones.

Wadud and Huda (2019) correlate the perceived usefulness of travel time in autonomous vehicles with the activities that people may engage in. Their findings also indicate that, besides the trip purpose, the direction (driving to work vs. driving from work back home) influences desirable non-driving activities while riding in an AV. Apart from the role of activities, the perception of time spent in AV may vary for different user groups as well (Trommer et al. 2016).

Malokin et al. (2019) investigate the question to what extent the possibility of being able to use travel time productively influences the utility of the travel itself. Especially in the context of AV, this question becomes more and more important. They performed a revealed preference survey to measure travel multitasking attitudes and behaviors of North Carolina commuters. Results indicate that $1.5 \%$ of these commuters would switch from public transport or carpools to a private car to drive alone if they would not be able to use their laptop or tablet during the commute time anymore. Assuming autonomous vehicles to be available, the drive-alone share would increase by $1.5 \%$ as these vehicles offer the possibility of multitasking and consequently reducing travel time disutility.

Of course, the results depend on the focus of the study, e.g. the automation level of the vehicle, if the AV is privately-owned or shared or if the trip purpose is commuting or leisure. Still, these studies show that the way people perceive travel time differs for trips with AV, which must be considered in a travel demand model. Additionally, changed travel times due to road capacity effects and valet parking options of AV should be considered in the choice models.

\section{Impacts on travel behavior}

In addition to the aforementioned studies on shared AV, there are also studies dealing with the effects of private AV on people's mobility behavior. In the following, a selection of these studies is summarized.

Gucwa (2014) examines the impacts of privately owned AV on urban travel using an activity-based model approach for the San Francisco Bay Area. Within the study, AV are assumed to be advanced and still require a driver to be present. Varied quantities are roadway capacity $(+10 \%,+100 \%)$ and the VOT (high quality rail, $-50 \%,-100 \%)$. Excluding the extreme assumption of zero time cost, results suggest an increase in vehicle miles traveled (VMT) of 4-8\% compared to the case without any AV.

Levin and Boyles (2015) integrate AV into a static four-step planning model and apply it for the Austin downtown network. They assume a capacity increase based on the 
speed-density relationship by Greenshields et al. (1935) and a reduced highway vehicle spacing at jam density for AV. Considering fully automated vehicles, empty (round-)trips for saving parking costs are possible while accepting higher fuel costs. For an AV-share of $100 \%$, public transport ridership decreases by around $61 \%$, while the number of person trips made by car roughly doubles and the number of vehicle trips increases by $271 \%$ because of a large share of empty vehicle trips. However, the capacity gains can compensate the increase in demand to some extent, resulting in an average link speed decreasing by $9 \%$.

An extension of the study can be found in Levin et al. (2019), which uses a dynamic model and looks more deeply into the effects of repositioning of AV. It is argued that the possibility to perform empty trips should not be banned by decision-makers, as this could motivate people to buy AV early and thus even improve traffic flow and reduce congestion because of the higher efficiency of AV.

Childress et al. (2015) investigate possible effects of AV with an activity-based model for the Seattle Region. Within four scenarios they vary road capacity, VOT for AV trips, parking costs and the AV business case. For the scenarios with different penetration levels of privately-owned AV, a capacity increase for freeways and major arterials of $30 \%$, a reduction of $35 \%$ for the AV users' VOT and parking costs being unchanged or reduced by $50 \%$, they find an increase of VMT between 4 and 20\%. The reason for this is an increase in car trips and the trip length. For $100 \%$ AV and reduced parking costs, vehicle hours traveled (VHT) increase by $17 \%$, otherwise, VHT decrease slightly.

Kim et al. (2015) also use an activity-based model to determine AV impacts for Atlanta in 2040 . For $100 \%$ AV, they examine scenarios in which additional assumptions are gradually incorporated: capacity gains by $50 \%$ because of cooperative adaptive cruise control (CACC), reduction of VOT by $50 \%$ because of higher productivity, reduction of operating costs by $70 \%$ and removal of parking costs due to possible relocating of AV. Across all scenarios, the number of car trips increases by 1-3\% while average trip length increases by around $20 \%$, both leading to $4-24 \%$ additional VMT. Capacity effects exclusively suggest a decrease of VHT by $9 \%$. Together with the reduction of VOT, VHT remain even to the baseline and with further cost reductions and neglecting empty trips VHT increase by $12 \%$.

Applying an activity-based model to the metropolitan area of Chicago, Auld et al. (2017) explore impacts of AV that are equipped with CACC. Assumptions mainly concern increases in road capacity of up to $80 \%$ and a range of VOT-reductions from 0 to $75 \%$ besides a range of given AV penetration rates. Changes in the modal share are not considered. Capacity benefits alone suggest an increase of $4 \%$ in VMT. A reduction of the VOT by $25 \%$ with no changes in capacity results in additional $12 \%$ VMT for a $75 \%$ AV-share. In the most extreme scenario with maximum capacity gains and $100 \% \mathrm{AV}$, VMT increase from $21 \%(-25 \%$ VOT) up to $79 \%(-75 \%$ VOT) together with a large increase in VHT $(+180 \%)$ and average travel times $(+230 \%)$.

Hörl et al. (2019a) conduct an agent-based simulation building upon the results of a cost structure analysis of future automated mobility services and a large mobility survey on intentions regarding mobility tool ownership and the use of conventional and automated means of transport. In a scenario with privately owned fully automated vehicles in Zurich and an assumed increase in capacity of $80 \%$, they find an increase of VMT by $40 \%$ in the city. This effect largely originates from changes in mode choice and only to a small extent from induced traffic $(0.5 \%)$.

Kröger et al. (2019) combine a vehicle technology diffusion model with an aspatial travel demand model and examine possible impacts of privately-owned fully automated vehicles for Germany and the USA. They assume a reduction in the VOT for AV by $25 \%$ 
from the eleventh minute of driving on and no changes in road capacity, but small time savings in access and egress times for car users. For a time horizon until 2035, they find an AV-share of 8-38\%, with an increase for car trips by 2-8\% and around 2-9\% more VMT.

Many of the presented studies are very similar in terms of representing the characteristics of AV. Key assumptions that occur in the vast majority involve changes in road capacity and travel time perception for trips in AV. These assumptions reflect associated capabilities of AV to have shorter reaction times and therefore to maintain shorter headways as well as the possibility to use the in-vehicle time for non-driving activities. Eventually, the lower generalized cost of car travel makes car modes very attractive and strongly influences mode and destination choice.

Model results show, if covered within the framework of the particular model, shifts in mode shares towards AV or car-driver respectively and an increase in trip lengths. Typically, vehicle mileage increases across-the-board, but total travel time spent does not necessarily increase as well, because the improved traffic performance due to AV can compensate for the effects. Nonetheless, it is not uncommon to see an increase in congestion in simulations. With the assumed reduction in perceived travel time, people are more willing to tolerate congestion and delay.

Modelers need to be able to vary such quantities and test a range in the model to see what demand effects the assumptions cause and at what scale they do so.

\section{Modeling methods}

It will take some time until vehicles can operate fully automated on all roads under all conditions. Derived from the capabilities of today's driving assistance functions, it can be assumed that the first generation of automated vehicles will only be able to drive automated on certain sections of the route. In automated mode, AV will act differently in traffic compared to CV. Hence, transport models must be able to capture their impact on traffic flow. AV will continue to require a driver with a driving license, but this person will be able to carry out non-driving activities for a certain period. This will change the person's perception of travel time.

In the following, we present two methods to integrate some impacts of automated vehicles in travel demand models. The first method extends macroscopic assignment models to include changes regarding traffic flow performance caused by AV. The second method provides an approach to include a differing perception of travel time in macroscopic travel demand models.

The presented methods are suitable for including AV as private vehicles but are not suitable for modeling shared AV as part of new on-demand business cases. This would require additional assumptions on the characteristics of the business case (fleet size, pricing, waiting times, pick-up and drop-off locations, accepted detour, etc.). Furthermore, methods for trip pooling and vehicle scheduling need to be integrated into the model. These extensions are important for evaluating the broader impacts of $\mathrm{AV}$, but are not within the scope of this paper.

\section{Traffic performance}

The American Highway Capacity Manual (2010) defines road capacity as the "maximum sustainable hourly flow rate at which persons or vehicles can be expected to 
traverse a point or a uniform section of a roadway during a given period under prevailing roadway, environmental, traffic and control conditions". This definition treats capacity as a constant value. Brilon et al. (2007) indicate that this assumption is not appropriate as observations show that the maximum traffic throughput varies even under constant external conditions. Instead of using constant capacities, they introduce the concept of stochastic capacities to replicate the relationship between traffic flow and traffic breakdown in a more suitable way. Lohmiller (2014) shows that the throughput on a motorway depends on the traffic composition, i.e. the driver population influences the quality of the traffic flow. This leads to two general interpretations for the relationship between demand, capacity and performance: The performance, which can be measured by the indicator delay time per vehicle, depends either on variable capacity values or on the ability of a given demand composition (driver/vehicle population) to use a given constant capacity.

Macroscopic assignment models for private transport apply volume-delay functions (VDF) to calculate travel time in the road network. For links, the travel time is computed by multiplying the free-flow travel time with a factor that is determined by a VDF as shown in Eq. (1). For nodes, a delay time is added to the free-flow travel time as Eq. (2) shows. Equation (3) presents a simple example of a VDF. The VDF factor depends on the volumecapacity ratio, i.e. the saturation rate $x_{s}$ of a supply element $s$, which represents either a link or a node. Equation (4) describes the relationship between volume and capacity applying the commonly used concept of passenger car units (PCU). This concept provides that capacity and vehicle volumes are converted into passenger car equivalents. It is commonly used in macroscopic assignment models. Examples for vehicle type specific PCU values are 1.0 for conventional passenger cars, 2.3 for heavy goods vehicles (HGV) and 0.4 for motorcycles (Kimber et al. 1982).

$$
\begin{gathered}
t_{s=\text { link }}\left(x_{s}\right)=t_{s}^{\text {free }} \cdot \operatorname{VDF}\left(x_{s}\right) \\
t_{s=\text { node }}\left(x_{s}\right)=t_{s}^{\text {free }}+\operatorname{VDF}\left(x_{s}\right) \\
\operatorname{VDF}\left(x_{s}\right)=1+\alpha \cdot x_{s}^{\beta} \\
x_{s}=\frac{\sum_{i \in \text { VehType }} q_{s, i} \cdot f_{i}^{P C U}}{q_{s}^{\max }}
\end{gathered}
$$

where $t_{s}\left(x_{s}\right)$ : travel time on supply element $s$ at saturation rate $x_{s}$ in sec, $t_{s}^{\text {free }}$ : travel time on supply element $s$ at saturation rate $x_{s}=0$ in sec, $\operatorname{VDF}\left(x_{s}\right)$ : volume-delay function with parameters $\alpha$ and $\beta, x_{s}$ : saturation rate (volume-capacity ratio) on supply element $s, i$ : vehicle type $i$ from the set of vehicle types VehType (e.g. CV, AV), $q_{s, i}$ : volume of vehicle type $i$ on supply element $s$ in veh/h, $q_{s}^{\max }$ : capacity of supply element $s$ assuming all vehicles are $\mathrm{CV}$ in PCU/h, $f_{i}^{P C U}$ : PCU of vehicle type $i$ in PCU/veh.

Assuming AV have a performance that differs from $\mathrm{CV}$ and depends on the types of supply elements it uses, we suggest extending the PCU concept to include AV as well as road and intersection types (motorway or urban road, grade-separated or at-grade intersections, signalized or unsignalized intersections). Since the PCU factor will be multiplied by the volume of the related vehicle type, it is possible to model the impacts of different penetration rates of AV. 
This extension can be implemented in two different ways, depending on the underlying assumptions. The first approach assumes a linear relationship between the share of AV and their impact on capacity. This requires a specific but constant PCU factor for each combination of vehicle type and supply element type as shown in Eq. (5). In this first approach, the PCU factor does not depend on the share of AV.

The second approach assumes a nonlinear relationship. In the case of a low penetration rate, the influence of a single $\mathrm{AV}$ is smaller than in cases with a higher penetration rate. To achieve this, the PCU factor must be adjusted during an assignment depending on the $\mathrm{AV}$-share on the specific supply element using Eq. (6). Its value ranges between the PCU factors for an $\mathrm{AV}$-share of $0 \%$ and $100 \%$. This function serves as a basic example. The goal is to find a function that represents the relationship between share and PCU of AV as well as possible. The function could also contain another, e.g. quadratic dependence to the AV-share.

Both concepts consider capacity as a constant value, which is not affected by AV at all. However, the demand volume is adjusted by using specific PCU factors depending on the AV itself as well as on the supply element to include impacts on traffic performance caused by AV.

$$
\begin{gathered}
x_{s}=\frac{\sum_{i \in \text { VehType }} q_{s, i} \cdot f}{q_{s}^{\max }} f= \begin{cases}f_{s, i=A V}^{P C U} & \text { linear impact AV } \\
f_{s, i=A V}^{P C U}\left(p_{s, A V}\right) & \text { nonlinear impact AV }\end{cases} \\
f_{s, i=A V}^{P C U}\left(p_{s, A V}\right)=f_{s, i=A V}^{P C U, 0 \%}-p_{s, A V} \cdot\left(f_{s, i=A V}^{P C U, 0 \%}-f_{s, i=A V}^{P C U, 100 \%}\right)
\end{gathered}
$$

where, $f_{s, i}^{P C U}$ : PCU of vehicle type $i$ on type of supply element $s$ in PCU/veh, $f_{s, i=A V}^{P C U}\left(p_{s, A V}\right)$ : PCU function dependent on the share of AV $p_{s, A V}$ in PCU/veh, $f_{s, i=A V}^{P C U, 0 \%}$ : PCU of vehicle type AV on $s$ for an AV-share of $0 \%$ in PCU/veh, $f_{s, i=A V}^{P C U, 100 \%}$ : PCU of vehicle type AV on $s$ for an AV-share of $100 \%$ in PCU/veh, $q_{s, i}$ : volume of vehicle type $i$ on supply element $s$ in $\mathrm{veh} / \mathrm{h}, q_{s}^{\max }$ : capacity of supply element $s$ in PCU/h.

Applying this method directly influences travel time for motorized private transport, which in turn is expected to have an impact on destination, mode and route choice as a key input. The magnitude depends on AV-share and the respective PCU values.

\section{Perception of travel time}

The utility of a particular travel choice depends on characteristics of the traveler, the trip purpose and the service quality of the mode. Besides costs and comfort, the perceived travel time represents an important part of the utility.

The way people perceive time during a trip depends on the type of activity they are engaged in: walking to a vehicle, waiting at a stop, being a driver or a passenger. To capture this perception in a choice model, every time component is weighted with a specific parameter to quantify the perceived travel time of a trip.

Highly automated vehicles driving automated on certain road types or network sections offer the possibility for the driver to spend some time of the trip on other tasks than driving. This share of the trip time is henceforth referred to as "automated travel time". Drivers will experience this time differently compared to the time driving a conventional vehicle.

Urban travel demand models distinguish a set of modes, e.g. car-driver and car-passenger, public transport, walking and cycling. Except for public transport and apart from 
walking as feeder, every mode uses exactly one means of transport. Since highly automated vehicles are assumed to be incapable of handling all traffic environments, they still require a driver with a driving license and therefore do not represent a new mode. This includes the assumption that AV are exclusively privately-owned and are not part of any new business case. Thus, the mode car-driver now covers two vehicle classes CV and AV with different characteristics.

The specific characteristics of AV can be integrated into existing travel demand models by adding a transport system AV with a specific utility function for route choice. Beside the already existing factor for travel time perception in $\mathrm{CV}$, this specific utility function applies an additional factor $\beta^{t, A V}$ to the automated travel time. This factor modifies the perceived travel time of a trip. To solely apply the factor to the automated travel time, this time must be tracked separately in the model. The non-automated travel time is not affected by this factor. Equations (7) and (8) show how the weighted travel time $v_{o d r}^{t}$ can be computed for $\mathrm{CV}$ and AV respectively.

$$
\begin{gathered}
v_{o d r}^{t, C V}=\beta^{t} \cdot t_{o d r}^{C V} \\
v_{o d r}^{t, A V}=\beta^{t} \cdot\left(t_{o d r}^{A V}-t_{o d r}^{A V, \text { automated }}+\beta^{t, A V} \cdot t_{\text {odr }}^{A V, \text { automated }}\right)
\end{gathered}
$$

where $v_{o d r}^{t, C V}, v_{o d r}^{t, A V}$ : weighted travel time for $\mathrm{CV}$ and $\mathrm{AV}$ for route $r$ from origin $o$ to destination $d, t_{o d r}^{C V}, t_{o d r}^{A V}$ : total travel time with a CV and AV on route $r$ from $o$ to $d$ in sec, $t_{o d r}^{A V \text {,automated }}$ : automated travel time with an AV on route $r$ from $o$ to $d$ in sec, $\beta^{t}$ : factor for travel time perception in $1 / \mathrm{sec}, \beta^{t, A V}$ : factor for automated travel time perception in an AV in $1 / \mathrm{sec}$.

People may not perceive any benefits for short periods traveling automated. Assuming that time usage depends on the duration of the automated section, a certain threshold value $t^{\varepsilon}$ (e.g. $\left.10 \mathrm{~min}\right)$ can be set by the model user. Consequently, the formula for weighted travel time with AV changes from Eqs. (8) into (9). Here, only the automated travel time exceeding the threshold results in a change of perceived travel time.

If possible, the automated travel times of all individual automated driving segments interrupted by manual driving should be tracked separately in the model. Then it can be ensured that the automated driving time is not composed of many short AV-ready sections from which the vehicle occupants would not benefit to the same extent as if they spent a long trip in automated driving mode.

$$
v_{\text {odr }}^{t, A V}=\beta^{t} \cdot\left(\left(t_{\text {odr }}^{A V}-t_{\text {odr }}^{A V, \text { automated }}+t^{\varepsilon}\right)+\beta^{t, A V} \cdot\left(t_{\text {odr }}^{A V, \text { automated }}-t^{\varepsilon}\right)\right)
$$

For mode and destination choice, one travel time matrix for the mode car-driver that represents the perceived travel times of $\mathrm{CV}$ and $\mathrm{AV}$ is required. This matrix $V^{t, C a r}$ replaces the previous travel time matrix of CV. As presented in Fig. 1 and Eq. (10) the aggregated weighted travel time for mode car-driver $v_{o d}^{t, C a r}$ is computed by weighting the transport system-specific travel times with the share of AV in the car fleet. This share is an input value defined by the model user.

$$
v_{o d}^{t, C a r}=\left(1-p_{A V}\right) \cdot v_{o d}^{t, C V}+p_{A V} \cdot v_{o d}^{t, A V}
$$

Where $v_{o d}^{t, C a r}$ : weighted travel time for mode car-driver from $o$ to $d, p_{A V}$ : share of AV in the car fleet, $v_{o d}^{t, C V}, v_{o d}^{t, A V}$ : weighted travel time of $\mathrm{CV}$ and $\mathrm{AV}$ from $o$ to $d$, 


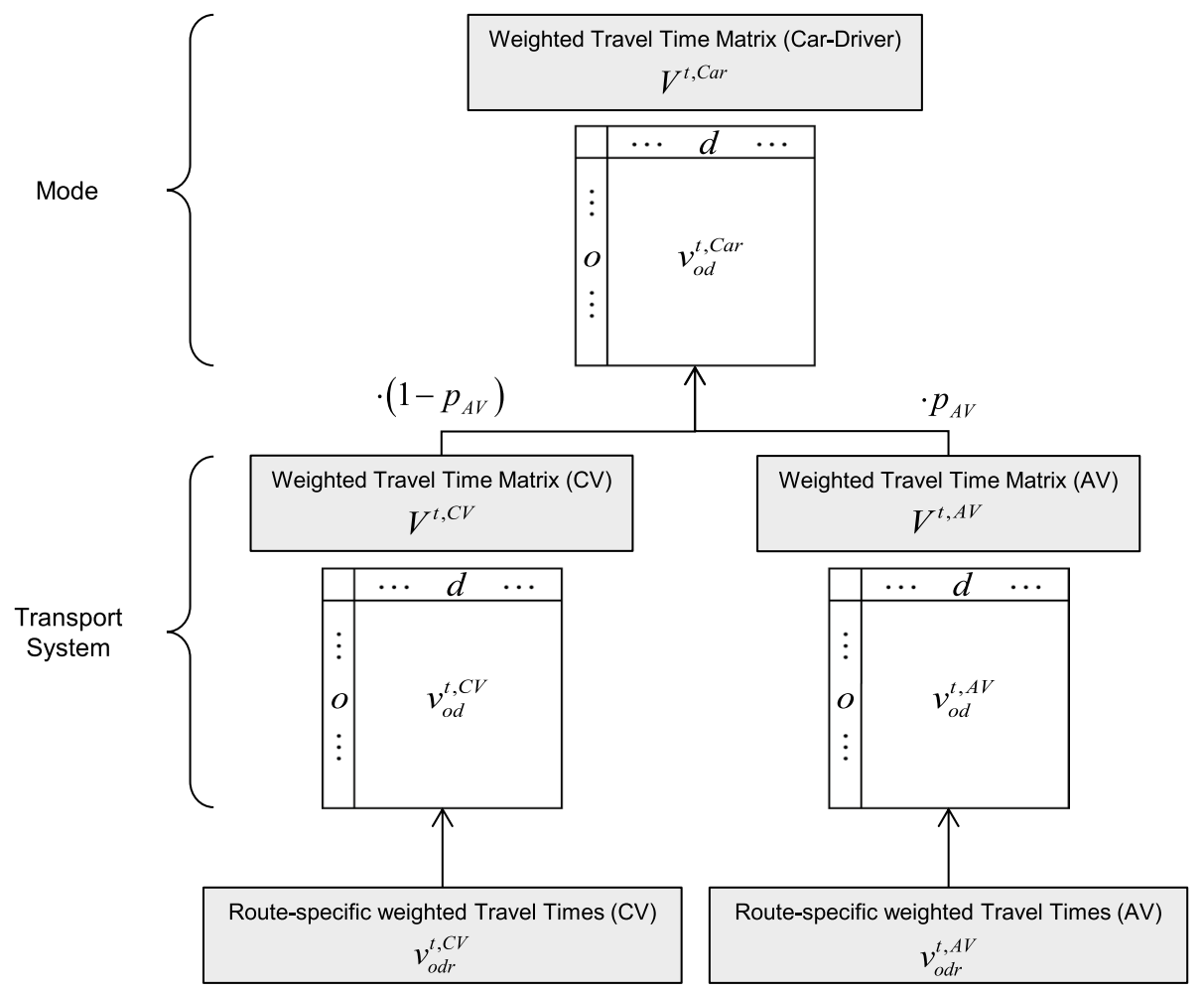

Fig. 1 Derivation of the weighted travel time for the mode car-driver from the transport systems AV and CV

The implementation of the presented method does not require any major modifications in an existing calibrated travel demand model but allows estimating demand effects of highly automated vehicles. The assumptions to be made have a major influence on the model results and are associated with uncertainties, as the equipment and functionality of highly automated vehicles are not yet known. Besides, the method assumes a uniform perception of automated travel time for all trips. This simplification could be resolved with time value factors that depend on person group and trip purpose.

A change in travel time perception, as implemented in the presented method, directly affects destination and mode choice, as the original travel time matrix is replaced by the adjusted one. For route choice, the modified perceived travel time has an indirect effect, because it is not updated during the assignment, but within the feedback loop in travel demand calculation. The effects scale with AV-share and the factor for travel time perception in AV.

\section{Application}

Within the CoEXist project, the presented modeling approaches are applied to the use case "Impacts of AV on travel time and mode choice on a network level". In this use case, the impacts of AV on travel time, destination choice, mode choice and route choice are examined with the macroscopic travel demand model of the Stuttgart Region. The use case 
focuses on identifying the impacts not just for single road facilities or selected network sections, but for the entire network within the study area.

\section{The Stuttgart region travel demand model}

Stuttgart is the capital of the state of Baden-Württemberg in Germany and is the center of the Stuttgart Region, which consists of about 180 other cities and smaller towns in five counties. The region is the economic center of the state with one quarter of the state's population and nearly one third of the economic power on $10 \%$ of the state's surface area.

The modes included in the model are car-driver, car-passenger, public transport, walking and cycling. The travel demand model includes the 2.7 million inhabitants of the region as well as public transport with 1200 lines, 50,000 vehicle runs, detailed stop points, fares and fare zones. Furthermore, it contains all operational and infrastructural measures that can be expected by 2025 . The demand is segmented in 1100 zones, 23 person groups and 19 trip purposes leading to 370 different demand groups, which originate from combinations of person group and concatenated trip purposes (activity chains). The demand model is an activity-chain-based model with an integrated destination and mode choice. The model calibration is based on a household survey, which covered 5000 households, 13,000 persons and 270,000 reported trips within a seven-day trip diary.

So far, the model has been applied successfully for the examination of more than 200 scenarios in approximately ten projects for the regional transportation plan and various local studies. The large number of successful applications indicates that the model produces reasonable results.

\section{Scenario dimensions}

The framework for the scenarios' settings follows Olstam and Johansson (2019). The aim is to cover a wide range of possible future states over the presumably long period during which both $\mathrm{CV}$ and AV will be driving on the roads. This period of coexistence is segmented into three stages:

1. Introductory: AV have been introduced, but the majority of vehicles are CV. Automated driving is generally constrained by limitations in technology.

2. Established: Automated driving has been established as a mode of high relevance. There is still a substantial share of CV.

3. Prevalent: Automated driving is the norm, but $\mathrm{CV}$ are still present.

In the course of these stages, the development of automated driving technology will progress. To account for this fact, the AV-classes Basic, Intermediate and Advanced are introduced and assigned to the stages Introductory, Established and Prevalent respectively. The AV-classes differ concerning their capabilities depending on the roadway type the AV is driving on. The distinguished roadway types are:

- Motorway: Multi-lane roads with physical barriers between directions and grade-separated intersections. 
- Arterial: Single or multi-lane roads with at-grade intersections. Bicycle and pedestrian traffic are separated from vehicle traffic either by physical barriers or medians. This roadway type includes urban and rural roads.

- Urban Street: Single or multi-lane roads with at-grade intersections. No clear separation between vehicle traffic and pedestrian and bicycle traffic. Despite the label Urban Street, which was used in the CoEXist project, this roadway type also includes rural roads.

These roadway types do not cover all roads present in the network. Feeder roads as the lowest level of roadway types are not considered appropriate for AV to operate automated throughout all scenarios.

Each of the 60 scenarios examined refers to one of the three stages, represents the situation with one penetration rate of AV (steps of 20\%), one associated AV-class and its assumed capabilities on every roadway type.

The assignment step applies a static deterministic user equilibrium model (DUE). This model class provides a unique solution for the total volumes measures in PCU. For a multiclass assignment DUE cannot guarantee unique solutions for each user class. To address these shortcomings, Bar-Gera (1999), Marcotte and Wynter (2004) and Gentile and Noekel (2009) proposed model extensions. As the assignment for this study distinguishes several user classes (CV, AV, HGV) we tested a traditional DUE and the extension provided by Gentile and Noekel (2009). The results show that the assignment method influences the aggregated values of distance travelled and time spent by less than $0.1 \%$.

\section{Assumptions}

To distinguish where AV can drive in automated mode, the term "AV-ready" was introduced within the CoEXist project. It represents the characteristics supply elements must have to be considered appropriate for automated driving. For supply elements that are not AV-ready, a person needs to be in charge of driving the vehicle. This distinction is implemented by introducing an additional attribute "AV-readiness" for every supply element. For supply elements, where AV cannot operate automated, the PCU factor is considered the same as for $\mathrm{CV}$, being 1.0. Furthermore, the driver perceives the travel time on this supply element not different from travel time in a CV.

The scenarios distinguish two settings for an AV-ready road network:

1. network $\hat{=}$ motorways: AV can operate automated only on the motorway network. This limitation can be caused not only by the capabilities of AV but also by regulatory measures.

2. network $\hat{=}$ all main roads: AV can operate on all main roads, i.e. all roadway types apart from feeder roads that have limited width.

\section{Traffic performance}

The examined scenarios do not include impacts of automated HGV on traffic performance. Applying the method of PCU factors requires the introduction of a PCU factor for every combination of AV-class and roadway type. Within the CoEXist project, the PTV Group, a company that provides the transport modelling software packages Visum and Vissim, conducted extensive microscopic traffic flow simulations (Fléchon et al. 


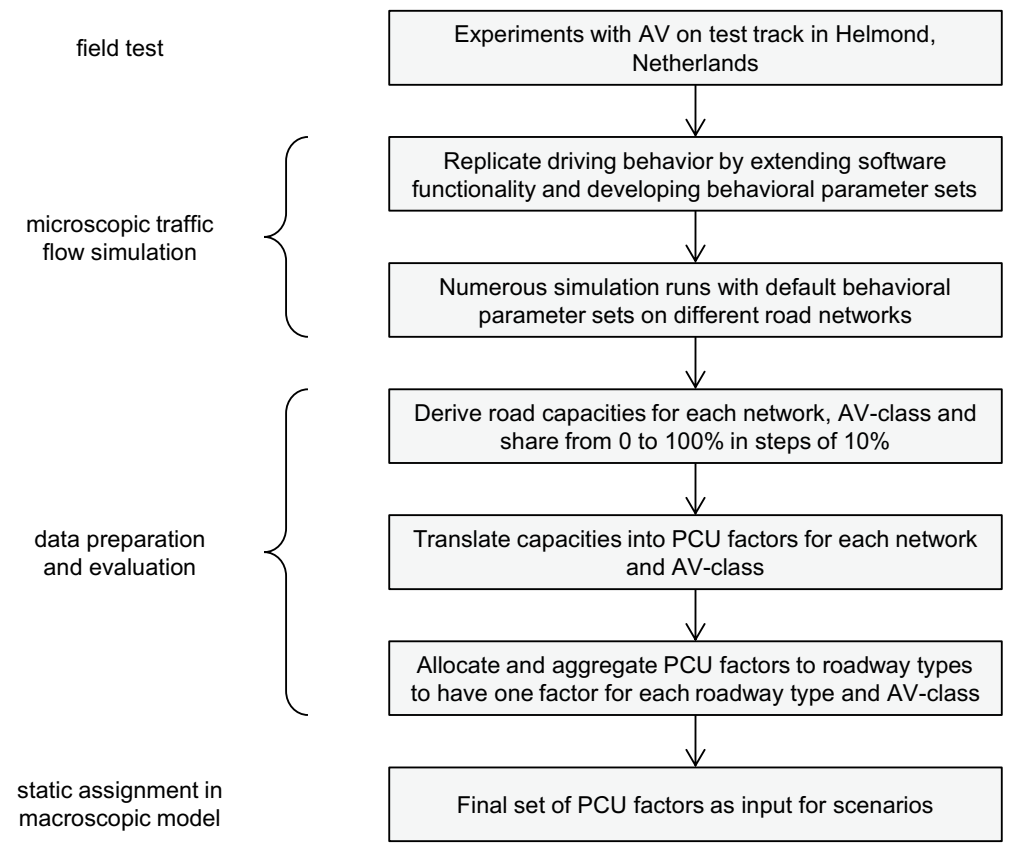

Fig. 2 The path from real test drives with AV to PCU factors for AV

Table 1 PCU factors for AV-classes on different roadway types (Sonnleitner and Friedrich 2020b)

\begin{tabular}{llll}
\hline & Basic AV & Intermediate AV & Advanced AV \\
\hline Motorway & 1.20 & 0.77 & 0.73 \\
Arterial & 1.26 & 0.81 & 0.76 \\
Urban street & n/a & 1.32 & 0.85 \\
\hline
\end{tabular}

2019), providing data for deriving PCU factors (Sonnleitner and Friedrich 2020a). In these simulations, AV-classes, the share of AV and the type of road facility were varied. The driving behavior of each AV-class is derived by analyzing AV prototypes on a test track in Helmond in the Netherlands and supplemented by assumptions (Sukennik et al. 2018b). Analysis of the observed capacities determined in the microscopic traffic flow simulations reveals that constant PCU factors fit the data better than the nonlinear factor from Eq. (6). Figure 2 shows the work steps from field test to final PCU factors.

The resulting PCU factors are shown in Table 1. It should be emphasized that these values should not be considered as exact values for the influence of AV across-theboard. They merely represent as best as possible the driving behaviors' performance of the test vehicles and serve as an assumption for the scenarios presented in this paper.

These values are only considered if a road of a specific roadway type is AV-ready. Besides, for Basic AV, no automation is available on urban streets, since it is assumed that the driving task is too demanding for AV of this class. Furthermore, the PCU factors base upon driving behavior without cooperative driving functionality. They do not represent increased performance through valet parking either, as this was not explicitly considered. 
The impact of AV on traffic performance is implemented in the assignment model without changing the VDF and the capacities. The VDF just needs to be extended to include PCU for AV depending on the roadway type.

\section{Perception of travel time}

As explained in the section on modeling methods, no new mode will be introduced, but AV will be part of the mode car-driver as an additional vehicle class. The basic assumption for varying the perception of automated travel time is that it will be either unchanged or reduced. This leads to the following three different settings for the scenarios:

1. perception $\hat{=} \pm 0 \%$ : no changes, travel time in an $\mathrm{AV}$ is perceived in the same way as in a CV

2. perception $\hat{=}-15 \%$ : perceived travel time corresponds to the travel time in an $\mathrm{AV}$ exceeding $10 \mathrm{~min}$ reduced by $15 \%\left(\beta^{t, A V}=0.85 ; t^{\varepsilon}=10 \mathrm{~min}\right)$

3. perception $\hat{=}-30 \%$ : perceived travel time corresponds to the travel time in an $\mathrm{AV}$ exceeding $10 \mathrm{~min}$ reduced by $30 \%\left(\beta^{t, A V}=0.70 ; t^{\varepsilon}=10 \mathrm{~min}\right)$

Cases 2) and 3) assume no benefits for the first ten minutes of automated travel time. Altogether, the assumed values lie in the range of the results of many studies presented in the literature review.

Since the model does not allow to distinguish between one and several automated driving segments within an assignment, only the sum of the automated driving time is considered. Travel time spent in an AV not operating automated, e.g. because the roadway is not AVready, is not considered for changes in perception.

\section{Experimental results}

The model computes a large number of indicators describing travel demand, supply quality and environmental impacts. Indicators relevant for this use case mainly focus on transport supply quality and travel demand:

- Number of trips by mode

- Person distance traveled by mode

- Vehicle distance traveled

- Person hours spent by mode

- Vehicle hours spent

Only trips with origin and destination within the Stuttgart Region are considered for the evaluation. The baseline scenario contains the network status of the year 2025 and assumes a car fleet consisting exclusively of conventional vehicles. 
Table 2 Examined scenarios and their characteristics

\begin{tabular}{llll}
\hline Scenario name & Stage of coexistence & AV-share (\%) & AV-class \\
\hline Base (0) & None (baseline) & 0 & - \\
Intro (20) & Introductory & 20 & Basic \\
Intro (40) & Introductory & 40 & Basic \\
Estab (40) & Established & 40 & Intermediate \\
Estab (60) & Established & 60 & Intermediate \\
Preva (80) & Prevalent & 80 & Advanced \\
Preva (100) & Prevalent & 100 & Advanced \\
\hline
\end{tabular}

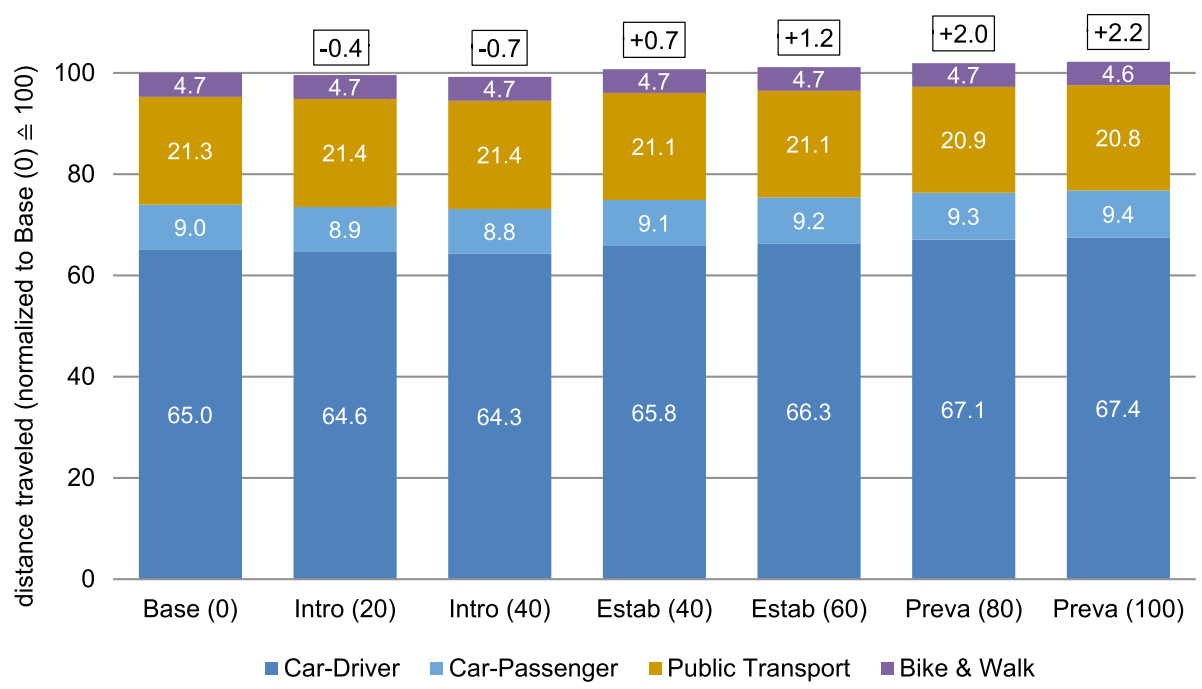

Fig. 3 Person distance traveled for 0 to $100 \%$ AV compared to the baseline scenario, AV-ready network $\triangleq$ motorways

\section{Transition from 0 to $100 \%$ AV-share}

To represent a possible progression from 0 to $100 \%$ AV-share, two scenarios of each stage with increasing levels of penetration and AV capability are compared with the baseline scenario. For reasons of clarity, only one AV-class is assumed to be present in each stage of coexistence. Table 2 shows the scenarios and the corresponding assumptions.

Each of the six settings with an AV-share $>0 \%$ is analyzed for two AV-ready network settings: network $\hat{=}$ motorways and network $\hat{=}$ all main roads. The settings lead to 13 scenarios including the baseline scenario. All these scenarios assume that perception of travel time for AV does not differ from $\mathrm{CV}$, to exclusively identify the scope of impact caused by changes in traffic performance.

Figures 3 and 4 show the person kilometers traveled per mode, normalized to the baseline scenario, for motorways or all main roads to be AV-ready respectively. The framed numbers above the bars indicate the change in total. If only motorways offer the possibility for AV to operate automated, the effects are not as large as for the extended AV-ready network but show the same trend. 


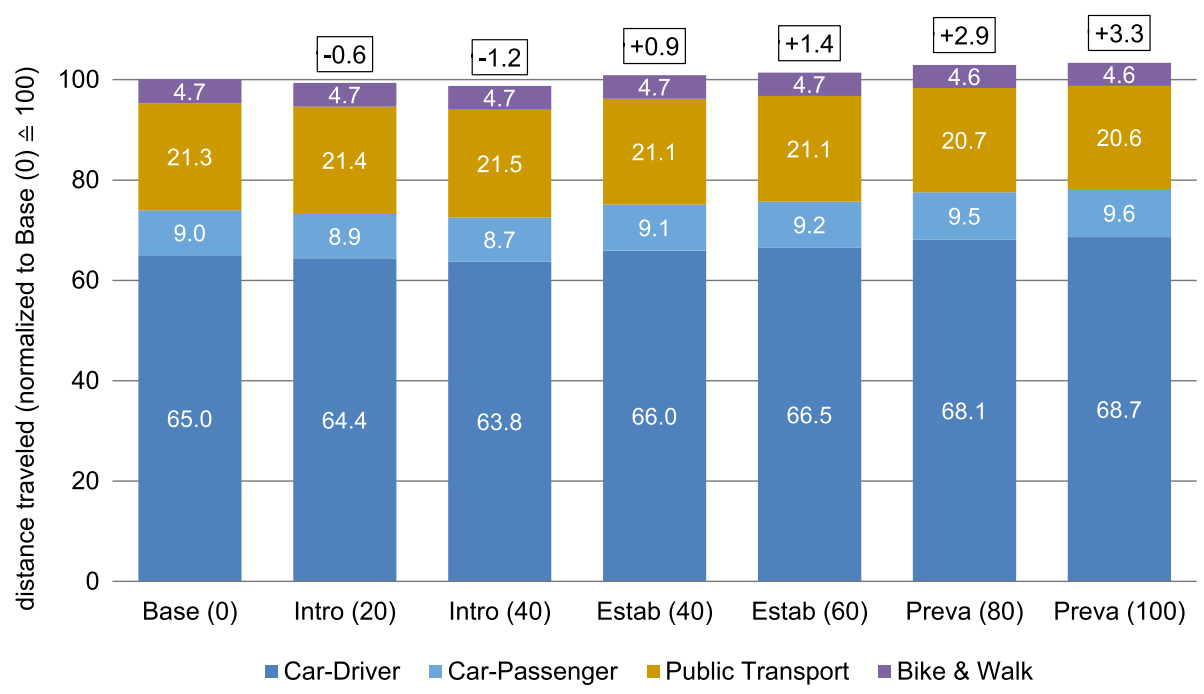

Fig. 4 Person distance traveled for 0 to $100 \%$ AV compared to the baseline scenario, AV-ready network $\triangleq$ all main roads

In the Introductory stage, person kilometers traveled of car-drivers, car-passengers and the total distance traveled decrease. The reason is a decline in traffic performance caused by Basic AV. This leads to increased travel times per road section, resulting in a shorter average trip distance for car users and a slight modal shift from car-drivers and car-passengers mainly to public transport. Person time spent by car users and in total remains almost unchanged.

As capabilities of AV improve and their share increases as assumed in the Established stage, results turn in the opposite direction. This holds for both AV-ready networks, even though for network $\hat{=}$ all main roads, AV perform worse on urban streets than CV. The increased performance of Intermediate AV on motorways is causing a modal shift from the active modes and public transport towards car-driver and car-passenger. If all main roads are AV-ready, i.e. AV operate automated also on arterials and urban streets, the change becomes even bigger. This means that the higher performance of AV on arterials outweighs the disadvantage of lower performance on urban streets. Additionally, average trip distances traveled by car users increase to a small extent for both cases compared to the baseline scenario. Therefore, person kilometers traveled increase for car trips and in total. For both network settings, the car modes' person time spent remains constant, although the respective modal share increases slightly.

The Prevalent stage implies the same correlations as the Established stage, but to a greater extent due to the higher share of AV and the vehicle class Advanced AV, performing better than $\mathrm{CV}$ on all roadway types. Related travel time savings of car users outweigh additional car trips and lead to a reduction in person time spent.

\section{Baseline versus prevalent stage with $80 \%$ AV-share and varied settings}

This section focuses on comparing the baseline scenario to all implemented scenarios of the Prevalent stage with a penetration rate of $80 \%$ Advanced AV. The purpose of this scenario group is to show the possible effects of a relatively high penetration rate of 
Table 3 Settings for prevalent scenarios regarding network and travel time perception
AV-ready network

Automated travel time perception

$(\%)$

\begin{tabular}{lc}
\hline Motorways & \pm 0 \\
All main roads & \pm 0 \\
Motorways & -15 \\
All main roads & -15 \\
Motorways & -30 \\
All main roads & -30 \\
\hline
\end{tabular}

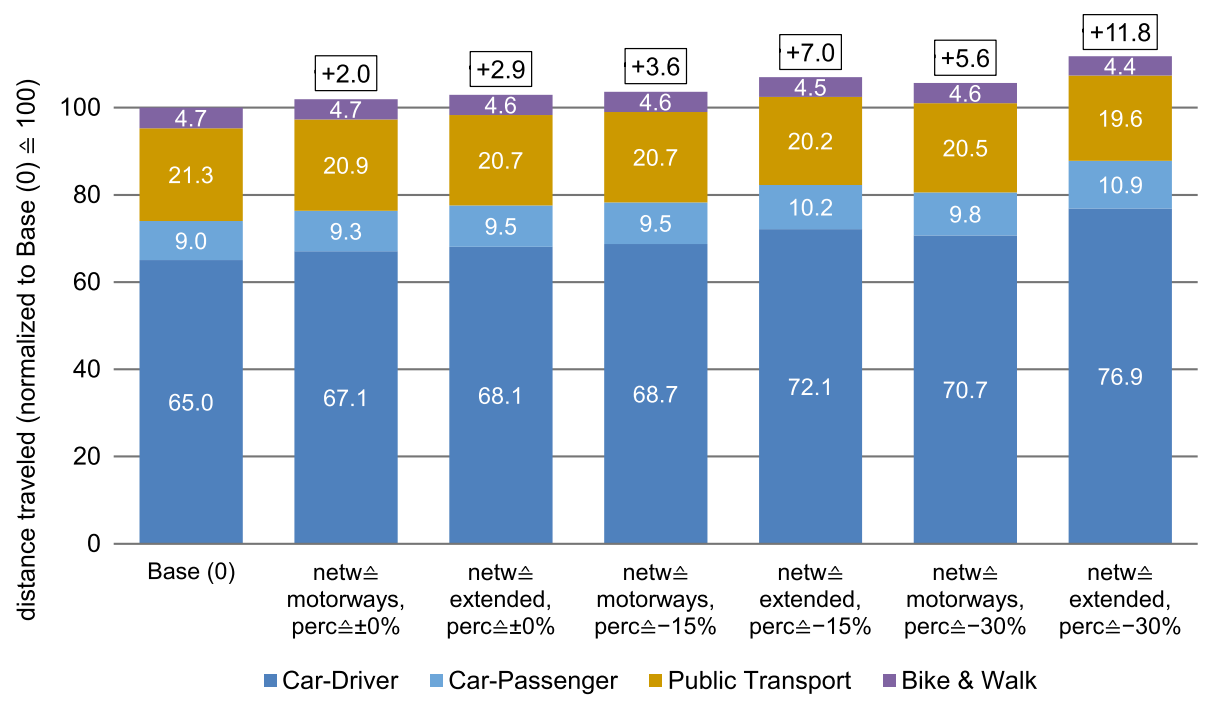

Fig. 5 Person distance traveled: Base (0) versus Prevalent (80) scenarios with varied settings regarding AVready network (netw) and travel time perception in AV (perc)

efficient AV together with the variation of travel time perception. The scenarios cover both AV-ready networks and benefits resulting from perceived automated travel time. These different settings are combined into six scenarios of the Prevalent stage as Table 3 shows.

Figure 5 shows the distance traveled, normalized to the baseline. Person kilometers traveled increase in total and for the modes car-driver and car-passenger for all six scenarios with AV compared to the baseline. The more extensive the AV-ready network and the bigger the benefits from a reduction in perceived automated travel time, the bigger the increase. Again, the increase comes from changes in the destination choice and modal shifts due to shorter travel times for car users. More destinations can be reached within a similar perceived travel time. This leads to increased average trip distances for trips made by car.

Consequently, vehicle distance traveled increases as well. Reducing the perceived travel time for AV on motorways by $15 \%$ leads to an increase of vehicle distance traveled by $5 \%$. If all main roads are AV-ready, this growth doubles. With a benefit in perceived time of 
$30 \%$ when driving automated, vehicle distance traveled increases by almost $20 \%$ compared to the baseline scenario.

Figure 6 shows the time spent for the same set of Prevalent scenarios compared to the baseline. If perception is assumed unchanged, person hours traveled decrease in total. The higher performance of $\mathrm{AV}$ leads to a shift from public transport and active modes to the faster mode car. Once a reduced perceived travel time in AV is considered, the total time spent increases, because the modal shift towards the car modes exceeds the performance gains. People are also willing to spend more time in their vehicles since it is perceived less inconvenient than in $\mathrm{CV}$.

The results confirm the expectation that highly automated vehicles if operating efficiently, increase the attractiveness of the car. This is likely to magnify the impact of motorized private transport, which will happen at the expense of all traffic participants. This phenomenon indicates a rebound effect: an improvement eventually leads to overall deterioration. In this case, capacity gains and reduced perceived travel time lead to more road traffic which then outweighs the gains.

\section{Assessment and discussion of results}

The trends in travel demand changes that occur in the scenarios are consistent with expectations: There are modal shifts and changes in destination choice depending on the attractivity of the mode car. However, aggregated figures do not reveal specific influences on route choice. More detailed evaluations show that, especially in the scenarios considering only the motorway network as AV-ready, more mileage is assigned to roads of this roadway type.

To assess the model's sensitivity to the assumptions made, the results are compared with the findings of the studies presented in the literature review. In general, our results match the trend of impacts regarding vehicle distance traveled and mode share of private

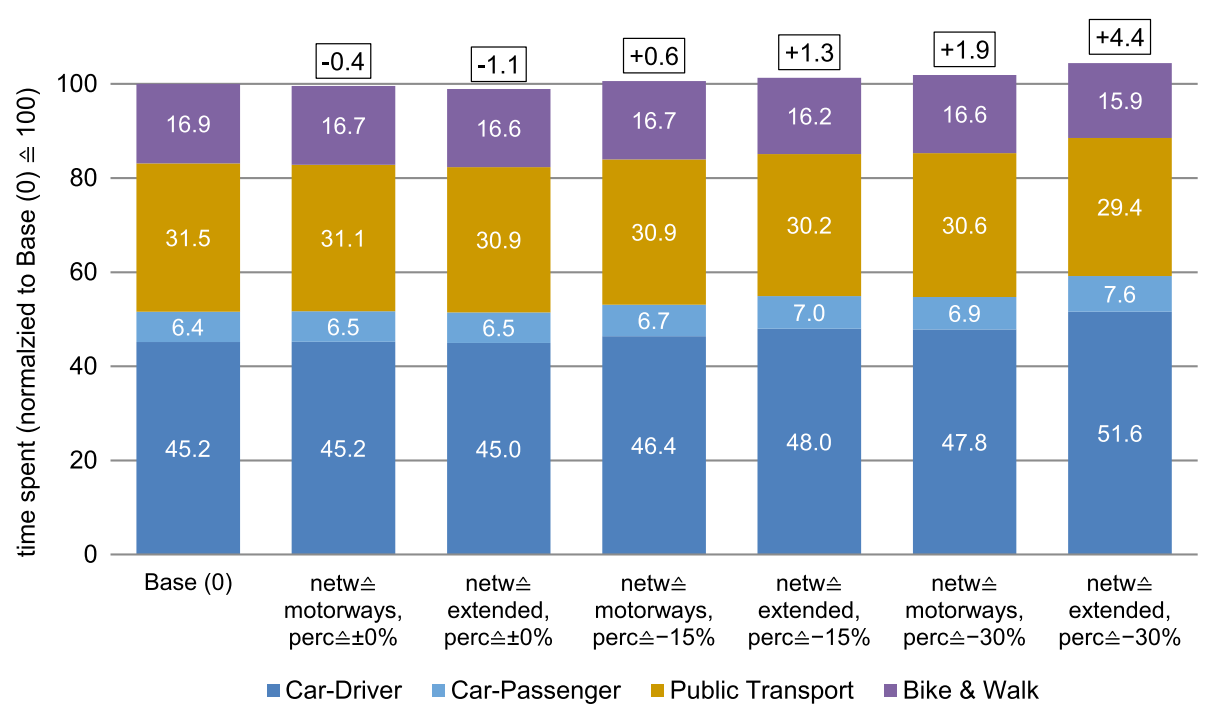

Fig. 6 Person time spent: Base (0) versus Prevalent (80) scenarios with varied settings 
transport (if considered). Since most studies examine fully automated vehicles with complete market penetration, a numerical comparison for the scenarios of the Prevalent stage with Advanced AV and as well as high AV shares seems appropriate.

For $100 \%$ AV and solely impacts on capacity, the Stuttgart Region model suggests an increase in VMT up to 6\%. Auld et al. (2017) find additional 4\% of VMT for Chicago, although assuming an $80 \%$ gain in capacity. Adding the impact of AV on the perception of travel time in our study, $80 \%$ AV-share cause an increase of VMT by up to $9 \%$ for the motorway network and $18 \%$ for all main roads to be AV-ready. This clearly shows that assumptions on travel time perception influence results to a greater extent. It compares with the 4-24\% increase of VMT if we summarize the results of studies whose assumptions are consistently more extreme, but still similar to ours (Gucwa 2014; Childress et al. 2015; Kim et al. 2015; Auld et al. 2017).

The magnitude of the presented results is in the range of those of other studies. However, this consistency should not be overstated, as there are numerous differences in terms of assumptions and simplifications. Most studies look at fully automated vehicles, which is why some effects are already out of scope for our case study assuming highly automated vehicles requiring a driver. Such effects concern induced traffic by people without a driving license or with mobility impairments and relocating of vehicles on their own, which in turn excludes additional traffic from empty trips and effects from changes in parking pressure and parking cost avoidance. Furthermore, this study neglects a more realistic way of introducing AV to the private vehicle fleet in the model by setting the share instead of forecasting it. To give good examples, Kröger et al. (2019) apply a vehicle diffusion model and Levin and Boyles (2015) gradually introduce AV-ownership depending on household income. Also, other studies include travel demand impacts through changes in operating costs (Kim et al. 2015), parking costs (Levin and Boyles 2015; Childress et al. 2015) and reductions in access and egress times (Kröger et al. 2019) because of a more efficient parking process.

This study stands out due to the focus on stages of coexistence. An attempt is made to represent the presumably long transition period to full AV market penetration. Within this period, it is assumed that first-generation AV may worsen traffic performance for a while. Nonetheless, travelers may benefit from no longer having to drive themselves because they can make better use of their time. Another aspect of high importance to this study is the distinction of roadway types and their respective AV-readiness. Especially for the first years of coexistence between $\mathrm{CV}$ and $\mathrm{AV}$, it may be crucial to know what difference the density of the road network that AV can operate automated makes to people's mobility behavior.

\section{Summary and conclusion}

As with all models, travel demand models can only do what the model developer specifies. Despite known and unknown shortcomings, travel demand models are an important tool for transport planning, provided that they are reasonably built and validated with observed values. So far, the uncertainty of a travel demand forecast has mainly resulted from uncertainties in population growth, economic development, future pricing structures, car ownership and in people's mobility behavior per se. In the coming years, a revolution in vehicle technology will change the capability of vehicles and the way we use them. This makes it even more difficult to forecast future travel demand. Nevertheless, modeling probable 
technical developments regarding automated vehicles and regulatory measures can help planners and decision-makers to better understand possible impacts on future traffic.

This paper proposes modeling methods to integrate impacts of highly, but not fully automated vehicles into macroscopic travel demand models. Within the scope of this study, $\mathrm{AV}$ are privately-owned, highly automated and thus still require a person with a driving license. Hence, AV are not part of any new business case and also do not lead to new car trips by people without access to a car or with mobility impairments.

The purpose of these methods is to enable users of existing urban and regional models to easily extend their model by offering the possibility to apply a range of expected impacts of AV based on data or reasonable assumptions in a flexible manner. Incorporating effects of AV on traffic performance uses specific passenger car unit factors dependent on the roadway type and the capabilities of the particular AV-class. This method does not require new capacities in the model. Likewise, no changes regarding the volume-delay functions are considered. Further research should keep this in mind, as it may be that for certain roadway types and certain $\mathrm{AV}$-shares, the influence of $\mathrm{AV}$ is not correctly represented by original volume-delay functions.

The PCU factors used in this study are determined by evaluating data of microscopic traffic flow simulations. The underlying AV driving behavior sets are partly derived from observations of AV on a test track in Helmond, Netherlands and partly based on assumptions. With more data from field experiments with AV prototypes, driving behavior models could be improved. However, there will always be uncertainty when it comes to predicting traffic performance of automated vehicles which basically do not yet exist or have not yet reached series production readiness.

Highly automated vehicles allow their drivers to spend parts of the in-vehicle time on other activities. This leads to the assumption that the perception of travel time in AV differs from that in CV. The daily commute time including delays from congestion can then be used more efficiently turning a car gradually into a limousine service. The presented method uses a given AV penetration rate and a travel time perception factor for every road link as input. Currently, the method assumes one single factor for travel time perception in $\mathrm{AV}$ and therefore a uniform effect for all person groups and trip purposes. It then computes skim matrices of perceived travel time for $\mathrm{CV}$ and AV that are aggregated to one weighted travel time skim matrix. This matrix replaces the current skim matrix for the mode cardriver in the destination and mode choice step of the demand calculation. The travel time perception factor can only be assumed based on parameters of current models or parameters derived from stated preference surveys. New vehicle models are getting more and more automated driving functions. People may then be better able to imagine the benefits they can gain from not being in charge to drive themselves in various situations. The task is to identify and quantify such perception-related effects by conducting appropriate surveys. Model users will then be able to produce more meaningful and robust results.

Both methods are applied to the macroscopic travel demand model of the Stuttgart Region to examine possible impacts. In the study area, AV are assigned to a set share of the private car fleet. At the same time, no changes in car ownership due to AV are considered.

If first-generation AV are assumed to be rather cautious and thus performing worse than $\mathrm{CV}$, this would somewhat increase travel times for all motorized road users. For this case the model suggests minor modal shifts from car to other modes. As soon as AV improve traffic performance, traveling by car, either $\mathrm{CV}$ or $\mathrm{AV}$, becomes more attractive, causing a modal shift towards car. Additionally, people are willing to spend more time in their AV and therefore travel farther. Both circumstances lead to an increase in the distance traveled and the time spent. The impact on the modal split and the distance 
traveled correlates to the AV-share. The results indicate that road traffic may increase by around $20 \%$ solely because of the advanced capabilities of highly automated vehicles. Thus, the expected benefits of AV for individual car users do not come without substantial negative impacts resulting from more road traffic.

Policymakers should be aware of the impact vehicle automation may have on road traffic. Modeling results can serve as a basis for discussion on appropriate measures to mitigate negative impacts. Such measures would primarily cover well-known measures from transport planning which either encourage the usage of non-car modes (pull measures) or restrict car usage (push measures).

Acknowledgements This paper was developed as part of the research project "CoEXist-'AV-Ready" transport models and road infrastructure for the coexistence of automated and conventional vehicles" (h2020-coexist.eu) that has received funding from the European Union's Horizon 2020 research and innovation program under Grant Agreement No 723201. The authors would like to thank the reviewers for their thoughtful comments and efforts towards improving the manuscript.

Authors' contributions MF developed the model specification, JS and ER verified and implemented it. JS applied the model to the use case.

Funding Open Access funding enabled and organized by Projekt DEAL. This research is part of CoEXist, a project that has received funding from the European Union's Horizon 2020 research and innovation program under Grant Agreement No 723201.

Availability of data and material Related reports from the CoEXist project can be found at https://www. h2020-coexist.eu/resources/.

Code availability The software application PTV Visum was used.

\section{Declarations}

Conflict of interest The authors declares that they have no conflict of interest statement.

Open Access This article is licensed under a Creative Commons Attribution 4.0 International License, which permits use, sharing, adaptation, distribution and reproduction in any medium or format, as long as you give appropriate credit to the original author(s) and the source, provide a link to the Creative Commons licence, and indicate if changes were made. The images or other third party material in this article are included in the article's Creative Commons licence, unless indicated otherwise in a credit line to the material. If material is not included in the article's Creative Commons licence and your intended use is not permitted by statutory regulation or exceeds the permitted use, you will need to obtain permission directly from the copyright holder. To view a copy of this licence, visit http://creativecommons.org/licenses/by/4.0/.

\section{References}

Auld, J., Sokolov, V., Stephens, T.S.: Analysis of the effects of connected-automated vehicle technologies on travel demand. Trans. Res. Rec. 2625, 1-8 (2017)

Bar-Gera, H.: Origin-Based Algorithms for Transportation Network Modeling. University of Illinois at Chicago, Chicago (1999)

Bates, J.: History of demand modelling. In: Hensher, D.A., Button, K.J. (eds.) Handbook of Transport Modelling (Second Edition). Emerald Group Publishing Limited, Bingley (2008)

Bischoff, J., Maciejewski, M., Nagel, K.: City-wide shared taxis. A simulation study in Berlin. In: IEEE ITSC 2017. 20th International Conference on Intelligent Transportation Systems: Mielparque Yokohama in Yokohama, Kanagawa, Japan, October 16-19, 2017, pp. 275-280. IEEE, Piscataway (2017) 
Brilon, W., Geistefeldt, J., Zurlinden, H.: Implementing the concept of reliability for highway capacity analysis. Transp. Res. Rec. 2027, 1-8 (2007). https://doi.org/10.3141/2027-01

Childress, S., Nichols, B., Charlton, B., Coe, S.: Using an activity-based model to explore the potential impacts of automated vehicles. Transp. Res. Rec. 2493, 99-106 (2015). https://doi.org/10.3141/ 2493-11

Correia, GHd.A., Looff, E., van Cranenburgh, S., Snelder, M., van Arem, B.: On the impact of vehicle automation on the value of travel time while performing work and leisure activities in a car: theoretical insights and results from a stated preference survey. Transp. Res. Part A Policy Pract. 119, 359-382 (2019). https://doi.org/10.1016/j.tra.2018.11.016

de Looff, E., Correia, G.H.d.A., van Cranenburgh, S., Snelder, M., van Arem, B.: Potential changes in value of travel time as a result of vehicle automation: a case study in the Netherlands. In: 97th Annual Meeting (2018)

Fagnant, D.J., Kockelman, K.M.: Dynamic ride-sharing and fleet sizing for a system of shared autonomous vehicles in Austin, Texas. Transportation 45, 143-158 (2018). https://doi.org/10.1007/ s11116-016-9729-z

Fernandes, P., Nunes, U.: Platooning of autonomous vehicles with intervehicle communications in SUMO traffic simulator. In: 13th International IEEE Conference on Intelligent Transportation Systems (ITSC), 2010. 19-22 September 2010, Funchal, Madeira Island, Portugal, pp. 1313-1318. IEEE, Piscataway (2010)

Fléchon, C., Lohmiller, J., Sonnleitner, J., Sukennik, P., Dahl, A., Friedrich, M.: AV-ready traffic flow simulation models and assignments. In: 13th ITS European Congress, Brainport, Netherlands (2019)

Flügel, S., Halse, A.H., Hulleberg, N., Jordbakke, G.N.: Estimating the effect of vehicle automation on car drivers' and car passengers' valuation of travel time savings. In: 41th Annual Meeting of the Norwegian Association of Economists, Tromsø, Norway (2019)

Friedrich, B.: The Effect of Autonomous Vehicles on Traffic. In: Maurer, M., Gerdes, J., Lenz, B., Winner, H. (eds.) Autonomous Driving. Springer, Berlin, Heidelberg (2016). https://doi.org/10.1007/ 978-3-662-48847-8_16

Friedrich, M., Sonnleitner, J., Richter, E.: Integrating automated vehicles into macroscopic travel demand models. Transp. Res. Procedia 41, 360-375 (2019). https://doi.org/10.1016/j.trpro.2019.09.060

Gentile, G., Noekel, K.: Linear user cost equilibrium: the new algorithm for traffic assignment in VISUM. In: European Transport Conference, Association for European Transport (AET) (2009)

Greenshields, B.D., Bibbins, J.R., Channing, W.S., Miller, H.H.: A study of traffic capacity. Highw. Res. Board Proc. 14, 448-477 (1935)

Gucwa, M.: Mobility and energy impacts of automated cars. In: Proceedings of the Automated Vehicles Symposium, San Francisco (2014)

Hartmann, M., Motamedidehkordi, N., Krause, S., Hoffmann, S., Vortisch, P., Busch, F.: Impact of automated vehicles on capacity of the german freeway network. In: ITS World Congress 2017 Compendium of Papers (2017)

Heilig, M., Hilgert, T., Mallig, N., Kagerbauer, M., Vortisch, P.: Potentials of autonomous vehicles in a changing private transportation system - a case study in the Stuttgart region. Transp. Res. Procedia 26, 13-21 (2017). https://doi.org/10.1016/j.trpro.2017.07.004

Hörl, S., Becker, F., Dubernet, T., Axhausen, K.W.: Induzierter Verkehr durch autonome Fahrzeuge: Eine Abschätzung (2019a)

Hörl, S., Ruch, C., Becker, F., Frazzoli, E., Axhausen, K.W.: Fleet operational policies for automated mobility: a simulation assessment for Zurich. Transp. Res. Part C Emerg. Technol. 102, 20-31 (2019b). https://doi.org/10.1016/j.trc.2019.02.020

Kim, K., Rousseau, G., Freedman, J., Nicholson, J.: The travel impact of autonommous vehicles in metro atlanta through activity-based modelling. In: 15th TRB National Transportation Planning Applications Conference (2015)

Kimber, R.M., Semmens, M.C., Shewey, P.: Saturation Flows at Traffic Signal Junctions: Studies on Test Track and Public Roads. Proc. Int. Conf. Road Traffic, Institute of Electrical Engineers, London (1982)

Kröger, L., Kuhnimhof, T., Trommer, S.: Does context matter? A comparative study modelling autonomous vehicle impact on travel behaviour for Germany and the USA. Transp. Res. Part A Policy Pract. 122, 146-161 (2019). https://doi.org/10.1016/j.tra.2018.03.033

Le. Vine, S., Zolfaghari, A., Polak, J.: Autonomous cars. The tension between occupant experience and intersection capacity. Transp. Res. Part C Emerg. Technol. 52, 1-14 (2015). https://doi.org/10. 1016/j.trc.2015.01.002 
Levin, M.W., Boyles, S.D.: Effects of autonomous vehicle ownership on trip, mode, and route choice. Transp. Res. Rec. 2493, 29-38 (2015). https://doi.org/10.3141/2493-04

Levin, M.W., Smith, H., Boyles, S.D.: Dynamic four-step planning model of empty repositioning trips for personal autonomous vehicles. J. Transp. Eng. Part A Syst. 145(5), 4019015 (2019). https://doi. org/10.1061/JTEPBS.0000235

Lohmiller, J.: Qualität des Verkehrsablaufs auf Netzabschnitten von Autobahnen. Bewertung unter Berücksichtigung der Zuverlässigkeit und Analyse von Einflussfaktoren. Dissertation. Veröffentlichungen aus dem Institut für Straßen- und Verkehrswesen, vol 50, Stuttgart (2014)

Lu, Q., Tettamanti, T., Hörcher, D., Varga, I.: The impact of autonomous vehicles on urban traffic network capacity: an experimental analysis by microscopic traffic simulation. Transp. Lett. (2019). https://doi.org/10.1080/19427867.2019.1662561

Malokin, A., Circella, G., Mokhtarian, P.L.: How do activities conducted while commuting influence mode choice? Using revealed preference models to inform public transportation advantage and autonomous vehicle scenarios. Transp. Res. Part A Policy Pract. 124, 82-114 (2019). https://doi. org/10.1016/j.tra.2018.12.015

Marcotte, P., Wynter, L.: A new look at the multiclass network equilibrium problem. Transp. Sci. 38(3), 282-292 (2004). https://doi.org/10.1287/trsc.1030.0039

Olstam J, Johansson F (2019) Scenario specifications for eight use cases. CoEXist Deliverable D1.4, https:// www.h2020-coexist.eu/resources/

SAE International (2018) Taxonomy and Definitions for Terms Related to Driving Automation Systems for On-Road Motor Vehicles. https://saemobilus.sae.org/content/J3016_201806/. Accessed 01 Oct 2020

Shladover, S.E., Su, D., Lu, X.-Y.: Impacts of cooperative adaptive cruise control on freeway traffic flow. Transp. Res. Rec. 2324, 63-70 (2012). https://doi.org/10.3141/2324-08

Sonnleitner, J., Friedrich, M.: AV-ready macroscopic modelling tool. CoEXist Deliverable D2.7, https:// www.h2020-coexist.eu/resources/ (2020a)

Sonnleitner, J., Friedrich, M.: Guide for the simulation of AVs with a macroscopic modelling tool. CoEXist Deliverable D2.8. https://www.h2020-coexist.eu/resources/ (2020b)

Soteropoulos, A., Berger, M., Ciari, F.: Impacts of automated vehicles on travel behaviour and land use: an international review of modelling studies. Transp. Rev. 39, 29-49 (2019). https://doi.org/10.1080/ 01441647.2018.1523253

Steck, F., Kolarova, V., Bahamonde-Birke, F., Trommer, S., Lenz, B.: How autonomous driving may affect the value of travel time savings for commuting. Transp. Res. Rec. 2672(46), 11-20 (2018). https://doi. org/10.1177/0361198118757980

Stern, R.E., Cui, S., Delle Monache, M.L., Bhadani, R., Bunting, M., Churchill, M., Hamilton, N., Haulcy, R., Pohlmann, H., Wu, F., Piccoli, B., Seibold, B., Sprinkle, J., Work, D.B.: Dissipation of stop-and-go waves via control of autonomous vehicles: field experiments. Transp. Res. Part C Emerg. Technol. 89, 205-221 (2018). https://doi.org/10.1016/j.trc.2018.02.005

Sukennik, P., Lohmiller, J., Schlaich, J.: Simulation-based forecasting the impacts of autonomous driving. In: International Symposium of Transport Simulation (ISTS'18) and the International Workshop on Traffic Data Collection and its Standardization (IWTDCS'18). Transportation Research Procedia 2018 (2018a)

Sukennik, P., Zeidler, V., van Etten, J.: Technical report on data collection and validation. CoEXist Deliverable D2.6. https://www.h2020-coexist.eu/resources/ (2018b)

Talebpour, A., Mahmassani, H.S.: Influence of connected and autonomous vehicles on traffic flow stability and throughput. Transp. Res. Part C Emerg. Technol. 71, 143-163 (2016). https://doi.org/10.1016/j.trc. 2016.07.007

Tientrakool, P., Ho, Y-C., Maxemchuk, N.F: Highway capacity benefits from using vehicle-to-vehicle communication and sensors for collision avoidance. In: 2011 IEEE Vehicular Technology Conference (VTC Fall 2011). San Francisco, California, USA, 5 - 8 September 2011; [co-located with the Fourth IEEE International Symposium on Wireless Vehicular Communications (IEEE WiVeC 2011), pp. 1-5. IEEE, Piscataway, NJ (2011)

Transportation Research Board of the National Academies: Highway capacity manual. TRB Business Office, Washington, DC (2010)

Trommer, S., Kolarova, V., Fraedrich, E., Kröger, L., Kickhöfer, B., Kuhnimhof, T., Lenz, B., Phleps, P.: Autonomous Driving. The Impact of Vehicle Automation on Mobility Behaviour. (2016). https://www. ifmo.de/publications.html?t=45

Wadud, Z., Huda, F.Y.: Fully automated vehicles: the use of travel time and its association with intention to use. Proc. Inst. Civ. Eng. Transp. 1, 15 (2019). https://doi.org/10.1680/jtran.18.00134

Wagner, P.: Traffic control and traffic management in a transportation system with autonomous vehicles. In: Autonomous Driving: Technical, Legal and Social Aspects, pp. 301-316. Springer (2016) 
Publisher's Note Springer Nature remains neutral with regard to jurisdictional claims in published maps and institutional affiliations.

Jörg Sonnleitner studied Cybernetic Engineering at the University of Stuttgart from 2010 to 2016. Since his master's degree, he has been working as a research assistant and $\mathrm{PhD}$ student at the Chair of Transport Planning and Traffic Engineering at the University of Stuttgart. In the EU-project "CoEXist - 'AVReady' transport models and road infrastructure for the coexistence of automated and conventional vehicles" (2017-2020), funded by the Horizon 2020 framework programme, he investigated the impacts of automated vehicles on travel demand in the Stuttgart Region by extending an existing macroscopic travel demand model.

Markus Friedrich Since 2003 Prof. Dr.-Ing. Markus Friedrich is heading the Chair for Transport Planning and Traffic Engineering at the University of Stuttgart. From 1995 through 2003, Mr. Friedrich was in charge of the business unit Transport Planning Systems at the PTV AG in Karlsruhe. Here he headed the development of VISUM, one of the leading software packages for transport planning. Mr. Friedrich studied civil engineering and received his $\mathrm{PhD}$ from the Technical University Munich in 1994.

Dipl.-Ing. Emely Richter studied traffic engineering at the Technical University of Dresden. Since 2017, she has been a research assistant at the Chair for Transport Planning and Traffic Engineering at the University of Stuttgart. In the context of her pursued $\mathrm{PhD}$, she is working on the topic of integrating automated and shared vehicle fleets into macroscopic travel demand models. 